\title{
Endovascular plug for internal carotid artery occlusion in the management of a cavernous pseudoaneurysm with bifrontal subdural empyema: technical note
}

\author{
Sunil Manjila, MD, ${ }^{1}$ Gagandeep Singh, MD, ${ }^{2}$ Obinna Ndubuizu, MD, PhD, ${ }^{1}$ Zoe Jones, BA, ${ }^{3}$ \\ Daniel P. Hsu, MD, ${ }^{4}$ and Alan R. Cohen, MD ${ }^{5}$ \\ 1Division of Pediatric Neurosurgery, Rainbow Babies and Children's Hospital, Department of Neurological Surgery, The \\ Neurological Institute, University Hospitals Case Medical Center; '2Division of Interventional Neuroradiology, Department of \\ Radiology, University Hospitals Case Medical Center, Cleveland; ${ }^{3}$ Ohio University Heritage College of Osteopathic Medicine, \\ Athens, Ohio; ${ }^{4}$ Kaiser Permanente Neuroscience Center, Redwood City, California; and ${ }^{5}$ Division of Pediatric Neurosurgery, \\ Department of Neurosurgery, The Johns Hopkins Hospital, Baltimore, Maryland
}

\begin{abstract}
The authors demonstrate the use of an endovascular plug in securing a carotid artery pseudoaneurysm in an emergent setting requiring craniotomy for a concurrent subdural empyema.

They describe the case of a 14-year-old boy with sinusitis and bifrontal subdural empyema who underwent transsphenoidal exploration at an outside hospital. An injury to the right cavernous segment of the ICA caused torrential epistaxis. Bleeding was successfully controlled by inflating a Foley balloon catheter within the sphenoid sinus, and the patient was transferred to the authors' institution. Emergent angiography showed a dissection of the right cavernous carotid artery, with a large pseudoaneurysm projecting into the sphenoid sinus at the site of arterial injury. The right internal carotid artery was obliterated using pushable coils distally and an endovascular plug proximally. The endovascular plug enabled the authors to successfully exclude the pseudoaneurysm from the circulation. The patient subsequently underwent an emergent bifrontal craniotomy for evacuation of a left frontotemporal subdural empyema and exenteration of both frontal sinuses. He made a complete neurological recovery.

Endovascular large-vessel sacrifice, obviating the need for numerous coils and antiplatelet therapy, has a role in the setting of selected acute neurosurgical emergencies necessitating craniotomy. The endovascular plug is a useful adjunct in such circumstances as the device can be deployed rapidly, safely, and effectively.

https://thejns.org/doi/abs/10.3171/2017.3.PEDS16370
\end{abstract}

KEY WORDS endovascular plug; subdural empyema; pseudoaneurysm; carotid artery; sphenoid sinus; vascular disorders; surgical technique

$\mathrm{D}$ IRECT carotid artery injuries are rare but may be life threatening. Resulting pseudoaneurysms, or false aneurysms, are by definition extraluminal, contained hematomas, whereas true aneurysms show involvement of all 3 layers of the vessel wall. The pseudoaneurysm wall is composed only of the adventitial layer, adjacent tissues, or sometimes just by hematoma. Pseudoaneurysms also differ from a traumatic arterial dissection, where separation of the intimal layer from the outer layers occurs due to extravasation of blood. Pseudoaneurysms are rare, accounting for less than $1 \%$ of all intracranial aneurysms, but are associated with significant morbidity and mortality. ${ }^{22,25,29,47}$ These false aneurysms are typically caused by adjacent bone fractures due to trauma but can also be caused by iatrogenic arterial injury during neurosurgical procedures, such as aneurysm clipping, tumor removal, and transsphenoidal surgery. $2,3,10,36,44$ However, development of an internal carotid artery (ICA) pseudo-

ABBREVIATIONS ACA = anterior cerebral artery; $C C A=$ common carotid artery; $I C A=$ internal carotid artery; $M C A=$ middle cerebral artery

SUBMITTED July 9, 2016. ACCEPTED March 31, 2017.

INCLUDE WHEN CITING Published online June 16, 2017; DOI: 10.3171/2017.3.PEDS16370. 
aneurysm during and following transsphenoidal surgery is rare. Patients experiencing this condition are at an increased risk of ICA rupture, which then can result in epistaxis, subarachnoid hemorrhage, and carotid-cavernous fistula..$^{10,22,51}$

While severe hemorrhage due to an ICA pseudoaneurysm is life threatening, direct surgical clipping of such lesions usually proves to be difficult given the need for rapid hemostasis and the extensive skull base exposure required for a direct arterial repair. Although endovascular management (including coil embolization and covered stents) has emerged and gained increasing acceptance, significant therapeutic challenges remain. These challenges are due primarily to the friable nature of the pseudoaneurysms, their lack of an intact arterial wall, and issues with stable positioning of detachable coils..$^{21,29}$ Definitive microsurgical treatment may require parent vessel sacrifice or artery reconstruction with bypass grafting. ${ }^{21,22,41,49}$ Trapping and parent vessel sacrifice have long been established as a treatment option for intracranial aneurysms that are not amenable to surgical clipping or reconstruction. 1,11,15,20,21,42,48 Parent vessel sacrifice techniques also have their limitations, in that the patient might not tolerate the vessel sacrifice, resulting in a significant stroke unless there is adequate cross circulation. Thus, adequate integrity of the cerebral collateral circulation via the anterior and posterior communicating arteries must be ensured prior to intracranial ICA occlusion.

Here we demonstrate the use of an endovascular plug device for occlusion of an iatrogenic ICA pseudoaneurysm in a unique circumstance in which an emergent craniotomy for subdural empyema was necessary. The endovascular plug significantly decreased the duration and radiation exposure of the procedure, and it reduced the number of coils that are placed for a typical deconstructive therapy. Most importantly, this technique reduced the need for subsequent antiplatelet therapy, which would have been required had deconstructive endovascular management been performed using covered or bare-metal stents.

\section{Illustrative Case}

A 14-year-old boy was transferred from an outside hospital for torrential epistaxis following an iatrogenic right carotid artery injury during endoscopic sphenoid sinusotomy. He had presented initially to an outside institution with a 10-day history of fever and headaches that localized to the left orbital and mandibular region. He was initially treated with oral antibiotics for presumed acute sinusitis, after which his symptoms transiently improved; however, he continued to have spikes in temperature and subsequently developed progressive left periorbital swelling. CT and MRI showed paranasal sinusitis and extraaxial intracranial pus in the left frontal and temporal regions suggestive of an acute subdural empyema (Fig. 1). The patient underwent functional endoscopic sinus surgery involving bilateral sphenoidotomies at the outside hospital. A minimal amount of purulence was encountered, and a left sphenoidotomy was performed successfully. However, during the right sphenoidotomy there was torrential bleeding from the posterior aspect of the right sphenoid sinus
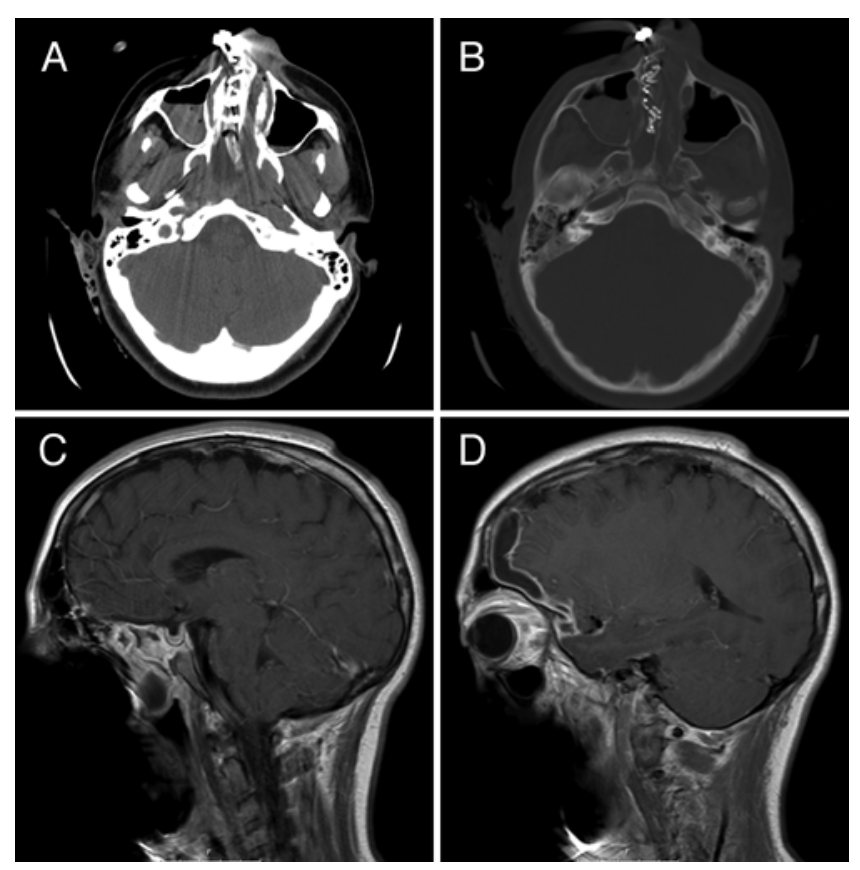

FIG. 1. A and B: CT images showing the right nostril packed with an inflated Foley catheter and cotton pledgets immediately after torrential epistaxis. C: Preoperative sagittal contrast-enhanced MR image showing active sphenoid sinusitis with intense enhancement. D: Sagittal contrast-enhanced MR image showing left frontal subdural empyema.

consistent with a carotid artery injury. Emergent packing of the sphenoid sinus and inflation of Foley catheter balloon rapidly controlled the bleeding. The patient was urgently transferred to our institution for further management after a screening head CT scan showed no evidence of intracranial hematoma.

The patient underwent sedation, orotracheal intubation, and mechanical ventilation. An indwelling Foley catheter was seen inserted into the right nostril and was inflated to tamponade the bleeding. On arrival to our hospital, the patient was still pharmacologically sedated. His pupils were equal and reactive to light. He had significant left periorbital swelling, and a left sixth cranial nerve paresis with proptosis. There was mild right facial weakness.

Emergent catheter-based angiography demonstrated abnormal dilation of the lumen of the horizontal cavernous portion of the right ICA (Fig. 2). There was a large associated pseudoaneurysm extending into the sphenoid sinus and a dissection flap within the cavernous segment of the ICA. Anterograde blood flow was appreciated within the ophthalmic, clinoidal, and communicating segments of the ICA. Anterograde opacification of the ophthalmic artery and its branches were seen with a robust choroidal blush. Flash filling across the anterior communicating artery complex was seen with filling of both $\mathrm{A}_{2}$ branches. A left ICA injection performed with cross-compression of the contralateral right common carotid artery (CCA) showed robust filling across the anterior communicating artery complex, with opacification of the distal right middle cerebral artery (MCA) and anterior cerebral artery (ACA) branches. Left vertebral artery injection with right CCA cross-compression also showed collateral reconsti- 

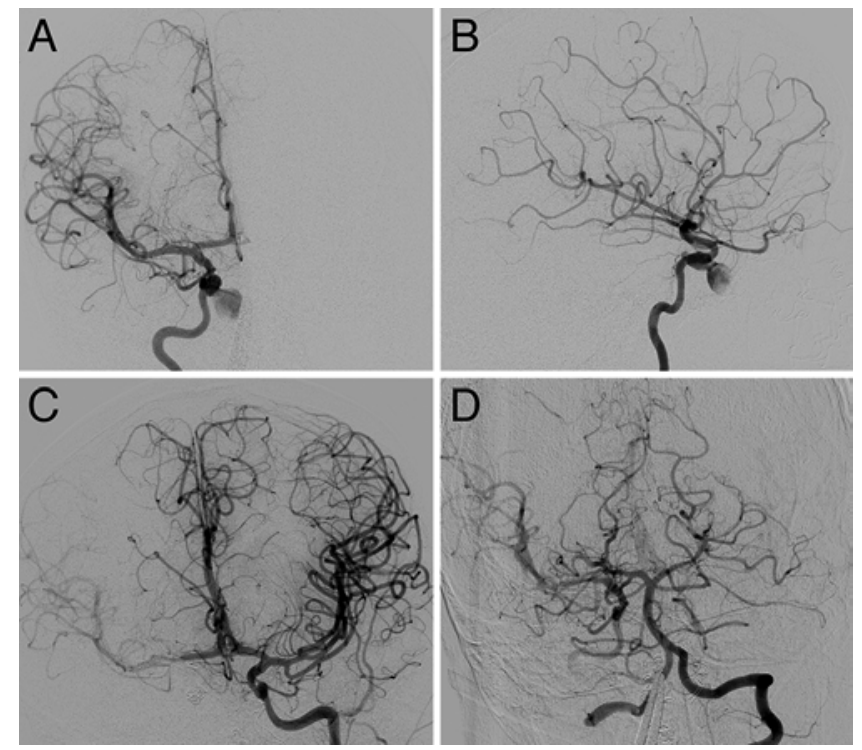

FIG. 2. A and B: Conventional right ICA angiograms, posteroanterior and lateral views, demonstrating dissection of the right cavernous carotid artery with a large pseudoaneurysm projecting into the sphenoid sinus at the site of arterial injury. C: Left ICA angiogram, posteroanterior view, performed with cross-compression of the contralateral right CCA, showing robust filling across the anterior communicating artery complex with opacification of the distal right MCA and ACA branches. D: Left vertebral artery injection with right CCA cross-compression showing collateral reconstitution of the right anterior circulation via the right posterior communicating artery.

tution of the right anterior circulation via the right posterior communicating artery.

In light of the patient's underlying pathological process (frontal sinus infection with associated subdural empyema), and given the adequate angiographically demonstrated collateral supply to the right anterior circulation through the right anterior and posterior communicating arteries, we chose to exclude the pseudoaneurysm from the circulation and treat the cavernous dissection. Consideration was given to vessel wall reconstruction and coiling of the pseudoaneurysm, alone. However, this was thought to be suboptimal due to the need for antiplatelet therapy after stent placement, given our plan for emergent evacuation of the subdural empyema.

\section{Procedure}

A balloon guide catheter was placed in the right ICA so that the embolization could be performed under flow arrest. A microcatheter was navigated over a microguidewire into the intracranial right ICA distal to the pseudoaneurysm. After confirming successful positioning proximal to the ophthalmic artery, we deployed a combination of pushable and detachable coils. An endovascular vascular plug device (Amplatzer, AVP II) was placed in the right ICA proximally through a 7-Fr concentric balloon guide catheter with an inner diameter of 0.059 inch. Postembolization angiography demonstrated complete proximal occlusion of the right ICA from the endovascular plug device with no retrograde filling of the pseudoaneurysm from the left ICA and left vertebral artery injections. Retrograde filling of the normal ophthalmic segment of the right ICA as well as the right ophthalmic artery was noted (Fig. 3). $\mathrm{CT}$ of the head and neck showed the presence of a patent distal cervical-segment ICA with an endovascular plug and the cavernous ICA containing pushable coils.

Following the procedure, which spanned approximately 2.5 hours, cranial MRI was performed. The images showed peripherally enhancing extraaxial fluid collections consistent with empyema around the anterior aspect of the left frontal pole and along the floor of the left anterior cranial fossa, with extension into the anterior aspect of the left middle cranial fossa and medial extension to the margins of the left cavernous sinus. The FLAIR hyperintensities were noted within numerous sulci of the left hemisphere, particularly in the left frontotemporal convexity cisterns suggestive of leptomeningeal inflammation or exudate. The hemostatic Foley catheter was left in the nostril, and the patient was left intubated. He was placed on vancomycin, meropenem, and gentamicin as well as dexamethasone and levetiracetam. Subsequently he was taken to the operating room urgently for evacuation of the subdural empyema.

\section{Operation}

The nasal packing was removed by the otolaryngology service, and the Foley catheter was deflated and removed along with numerous cottonoid pieces that were used for initial hemostasis. There was no active bleeding. A $0^{\circ}$ 4-mm Hopkins rod was then used to examine the nasal cavity, revealing a large clot in the right ostium as well as the right sphenoid rostrum. This clot was not disturbed. Examination of the left nasal cavity revealed minimal clot at the sphenoid rostrum although the remainder of the cavity appeared clear. After removing the throat pack at this point, the oral cavity and oropharynx were suctioned thoroughly. Transoral visualization of the oropharynx revealed no evidence of active bleeding or mucosal injuries.

Following the ENT procedure, a bifrontal craniotomy was fashioned with evacuation of a large left frontotemporal subdural empyema and exenteration of both frontal sinuses; repair was done using abdominal fat graft, fibrin thrombin glue, and a vascularized pericranial graft. Frank pus was encountered within the left frontal sinus. A $6-\mathrm{cm}$ linear incision in the left dura mater was made just above the orbital roof, and copious amounts of yellow creamy liquid pus were let out under pressure. More subdural empyema was evacuated by irrigation after which the brain relaxed. The dura was closed, and the frontal sinus was exenterated. A vascularized pericranial graft was laid over the dura and frontal sinus and was covered with more fibrin glue.

\section{Postoperative Course}

The patient remained intubated for 2 days and was treated with meropenem and ceftriaxone. Cultures later grew methicillin-sensitive Staphylococcus aureus and lactobacillus. The patient progressively improved over a period of 2 weeks, with gradual but complete resolution of his left sixth nerve palsy, right-sided facial weakness, and proptosis. The facial swelling resolved, and he made 

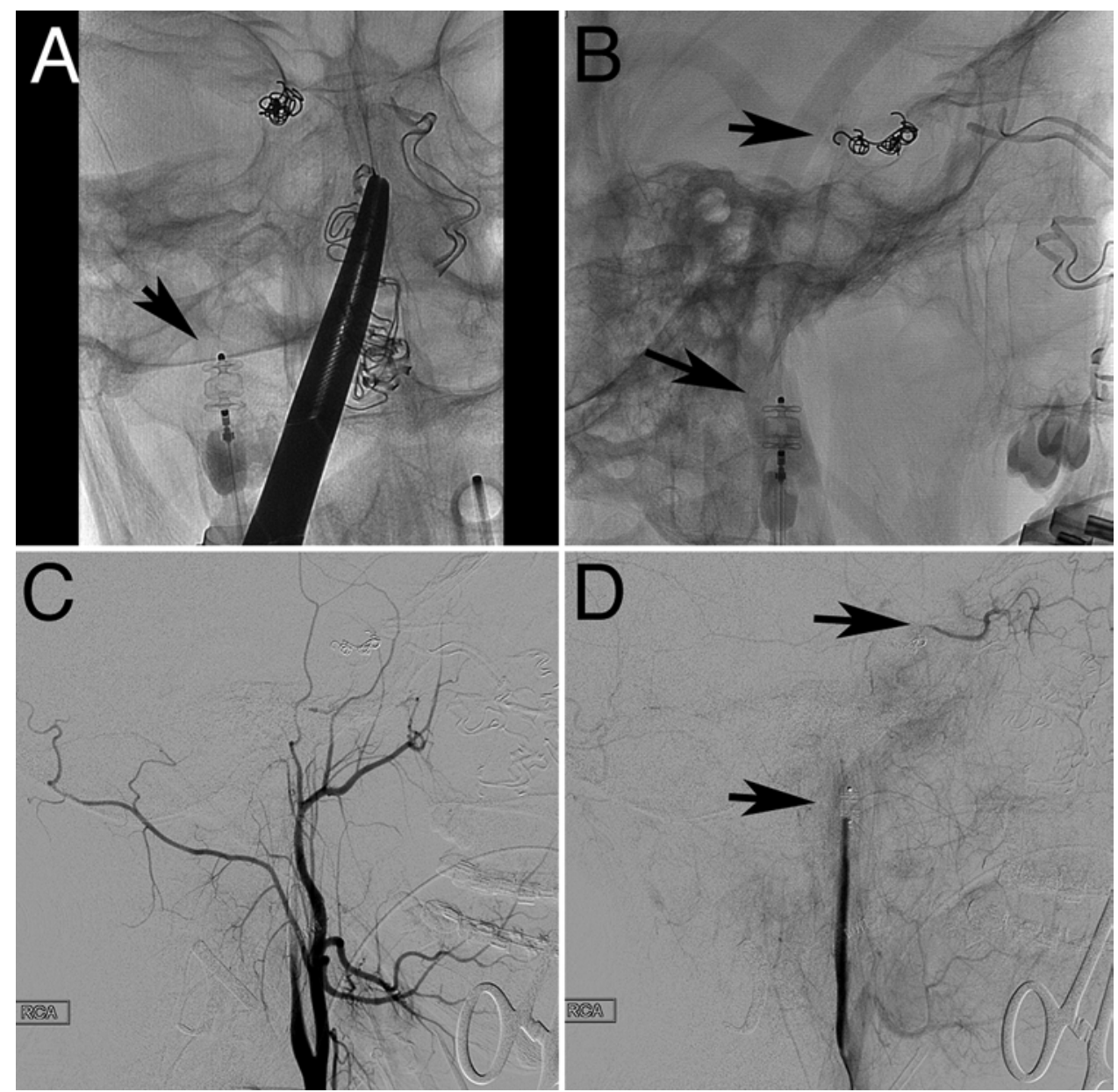

FIG. 3. A: Postprocedural angiogram showing extensive nasal packing and nonvisualized right ICA (arrow) distal to endovascular plug. B: Angiogram showing proximal endovascular plug and distal pushable coils in the parasellar ICA (arrows). C: Right CCA angiogram showing patent external carotid artery. D: Delayed view of right CCA injection showing remarkable contrast stasis in the internal carotid artery proximal to the endovascular plug (lower arrow) and reconstitution of the ophthalmic artery on the right via distal external carotid artery branches (upper arrow).

a complete neurological recovery. Of note, postoperative MRIs demonstrated empyema evacuation without evidence of hemorrhage (Fig. 4A and B).

\section{Discussion}

We have demonstrated the use of an endovascular plug device in the management of an iatrogenic carotid artery pseudoaneurysm (Fig. 4C and D). Patients with pseudoaneurysms are at risk for stroke caused by thromboemboli originating in the injured parent artery or within the aneurysm. ${ }^{22,34,35}$ The lack of an adequate aneurysm neck in these pseudoaneurysms makes the placement of surgical clips extremely challenging. Effective treatment may require trapping or excision of the lesion. ${ }^{8,29}$ These surgical techniques are confounded by high rates of morbidity and mortality due to increased risk of intraoperative rupture related to vessel fragility. ${ }^{40,47}$ As a result, management has shifted toward endovascular methods, including stent reconstruction, coil embolization, and parent vessel occlusion as demonstrated in our case. 14,27,29 $^{-2}$

Despite its increased usefulness, endovascular treat- ment is not without drawbacks because of the same anatomical and histopathological features that complicate surgical intervention. ${ }^{14,27,40}$ In an emergency intraoperative setting, endovascular treatment is considered the mainstay for the management of traumatic ICA pseudoaneurysms with acute uncontrolled bleeding, causing minimum systemic hemodynamic derangements. Many endovascular options are used to arrest flow of the parent artery close to the aneurysm. However, they still carry a significant risk of thromboembolism. Coil embolization could be more time consuming and expensive than endovascular plug placement. Coil embolization is associated with procedural complications including coil extrusions and lesion recurrence. ${ }^{43}$ Some authors have published work on the use of embolic agent such as Onyx (Medtronic) - an ethylene vinyl alcohol copolymer with dimethyl sulfoxide as a dissolvent-wherein the polymer precipitates in the lumen without sticking to the vessel walls. Agents such as Onyx HD-500 are used for treating traumatic ICA pseudoaneurysms. However, these have been reported as anecdotal cases, with a potential for later recanalization. ${ }^{7,29,32,33}$ 


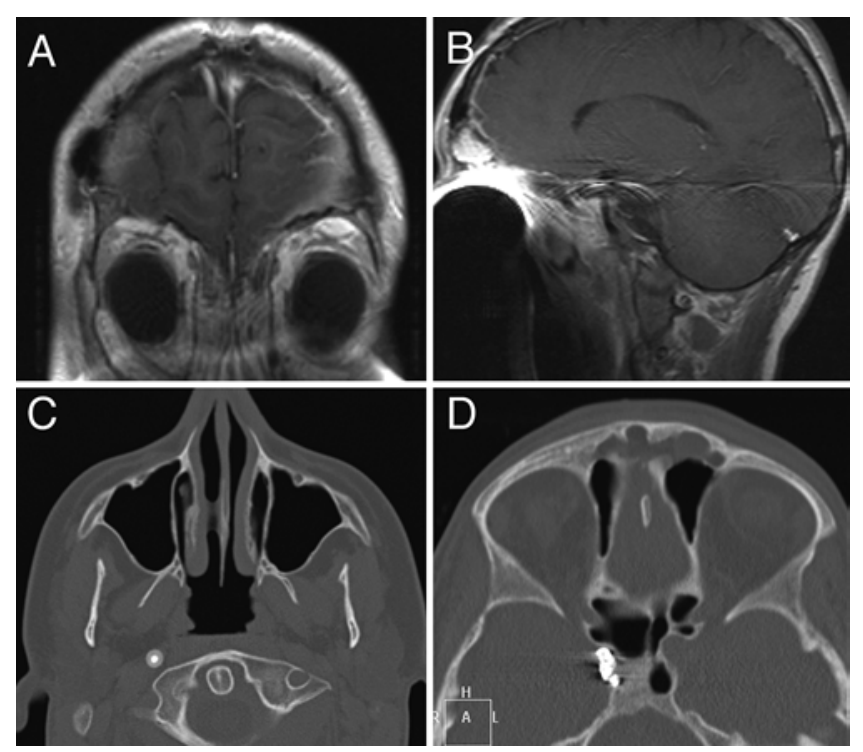

FIG. 4. A and B: Coronal and sagittal contrast-enhanced MR images showing resolution of the subdural empyema following craniotomy. C and D: Axial CT bone window scans showing right distal high cervical ICA endovascular plug and cavernous ICA containing pushable coils, respectively.

Alternative endovascular procedures such as porous stents, with and without coil embolization, have also been reported with variable success. ${ }^{9,38}$ Patients who are candidates for dual antiplatelet therapy should be considered for treatment with covered stents. ${ }^{43}$ Sylvester et al. reviewed literature on the management of ICA injuries in endonasal surgery and showed a higher rate of complications $(41.7 \%)$ with covered stents, including $8.3 \%$ rate of major technical complications in an institutional series. ${ }^{43} \mathrm{Kim}$ et al. have demonstrated successful use of Jostent covered stents (Abbott Vascular Devices) in a case of surgically sutured ICA tear that subsequently developed pseudoaneurysm. ${ }^{23}$ However, several other reports of covered stents have described problems with long-term patency and hemostasis, apart from the risk of potential cerebral ischemia. ${ }^{17,19,43}$ While coil extrusions are reported in association with porous stent-assisted coiling, specific complications with stent apposition and resultant endoleak have been reported for rigid covered stents, apart from embolic complications, branching artery perforations, and vasospasm. ${ }^{43}$ Deflatable balloons employed in endovascular therapy also achieve immediate hemostasis, although their use is limited by their significant learning curve, a long deflating time, and a cerebral ischemia rate of up to $15 \%-20 \% .^{18}$

Lee et al. have demonstrated successful extracranial occlusions using an endovascular plug device and noted that the deflatable balloons have the risk of unintentional detachment or early deflation and distal migration that can lead to disease recurrence and distal embolic complications. ${ }^{26}$

Most recently, flow-diverting devices, such as the Pipeline embolization device (Medtronic), have been used successfully without major technical complications. However, Tsang reported a case of complete extrusion of the Pipeline device through an occluded ICA 2 years after initial treatment, without any rebleeding. ${ }^{45}$ The significant therapeutic challenges posed by endovascular approaches that involve stents and flow diverters are primarily due to the friable nature of the pseudoaneurysms, their lack of an intact arterial wall, and delivery issues pertaining to these devices. Manipulation of the pseudoaneurysm during microcatheter, stent, or flow diverter placement also can increase the risk of intraprocedural rupture.

Direct surgical treatment of ICA pseudoaneurysms, on the other hand, by arterial resection or local reconstruction, has been associated with severe hemodynamic instability, reduced cerebral blood flow, and an increased risk of perioperative pseudoaneurysm rupture..$^{2}$ Trapping and parent vessel sacrifice have long been established as a treatment option for intracranial aneurysms that are not amenable to local surgical clipping or reconstruction. Parent vessel sacrifice techniques also have their limitations in that the patient might not tolerate the vessel sacrifice, resulting in a significant stroke unless there is adequate cross circulation. De novo aneurysm formation is another risk identified with carotid artery sacrifice, noted in up to $10 \%$ of patients. ${ }^{6,12}$ There is also an increased risk of enlargement of preexisting aneurysms, requiring periodic imaging follow-up in these patients. ${ }^{12}$ Considering the multicentric clinical experience on treating iatrogenic carotid artery pseudoaneurysms, we believe that the endovascular sacrifice is a quick salvage attempt, especially with a large vascular plug or flow diverter. This can be supplemented sooner or later with endovascular coils or tandem flow diverters, as the case may be. An option of repeated attempts at endovascular sacrifice in a delayed manner, with or without extracranial-intracranial circulation bypass, can be considered in patients with partial endovascular success. Alternatively, an early extracranialintracranial bypass with trapping of the ICA, depending on the adequacy of collateralization, may be considered once the primary vascular wall pathology has healed.

Intracranial pseudoaneurysms may arise from a variety of conditions and events, including sphenoidal and transsphenoidal surgery, trauma, mycotic seeding, and congenital collagen vascular diseases. In patients with posttraumatic or iatrogenic pseudoaneurysms of the cavernous ICA, the proximity of the vessel to the sphenoid sinus accounts for the massive epistaxis that is reported in many cases. ${ }^{27}$ An anatomical cadaveric study by Renn and Rhoton ${ }^{37}$ in 1975 showed that the ICA protrudes into the sphenoid sinus in up to $71 \%$ of people. The study also demonstrated that the bony wall of the sphenoid sinus covering the ICA was less than 1-mm thick in $66 \%$ and less than $0.5-\mathrm{mm}$ thick in $50 \%$ of the cadaver specimens. Furthermore, $4 \%$ of the specimens had no bone covering the ICA. Instead the vessel was covered only by dura mater and sinus mucosa. This anatomical relationship allows ICA aneurysms to expand anteromedially into the sphenoid sinus or posterior ethmoid air cells and rupture into the nose via the sphenoethmoidal recess. ${ }^{46}$

The medial anatomical location of the ICA with respect to the sphenoid sinus anatomy may predispose to massive epistaxis following pseudoaneurysm formation. Injury to the ICA during sinus surgery is rare and often fatal without timely and sufficient control of bleeding. ${ }^{50}$ The use of 
intrasinus packing for tamponading the blood loss can be performed emergently. However, there is a risk of rebleeding after removal of temporizing agents from the sinus. ${ }^{50}$ The endovascular device we employed was an Amplatzer Vascular Plug (AVP II), a self-expandable, detachable nitinol mesh intravascular device, which has been approved for arterial and venous embolization in the peripheral vasculature. Limited use has been described in the neurointerventional literature. $., 13,16,30,39$ The endovascular plug allows for prompt and durable vascular occlusion without the need for antiplatelet therapy, in contrast to detachable coil embolization and stent reconstruction. Furthermore, coils do not achieve an instantaneous occlusion after deployment. Coils allow slow-flowing blood to travel across an incompletely occluded vessel, potentially generating an embolic source at this site from either developing thrombus or migrated coils themselves. ${ }^{27}$ Detachable coil embolization of acute pseudoaneurysms may be susceptible to the risk of dislodgment by putting stress on the vessel wall. ${ }^{27}$ Fixed positioning of detachable coils is also complicated by distal coil migration, as the outward circular force may not be adequate to anchor the coil to the intimal wall of the vessel..$^{21}$ The compliance of the vascular wall can be especially counterproductive for coil-mediated occlusion in segments of the parent vessel not confined within a bony canal. ${ }^{21}$

The endovascular plug we used has a unique multisegmented, multilayered design that significantly reduces the time to occlusion for transcatheter embolization procedures (Fig. 5). The 3 lobes of the plug are designed to better conform to vessel landing zones. The plug has 6 layers of mesh, giving a relatively rapid time to vessel occlusion. The plug can be recaptured prior to final deployment, allowing for accurate placement. In the cases of active extravasation or sentinel hemorrhages from carotid artery injury, a device that can be deployed quickly and results

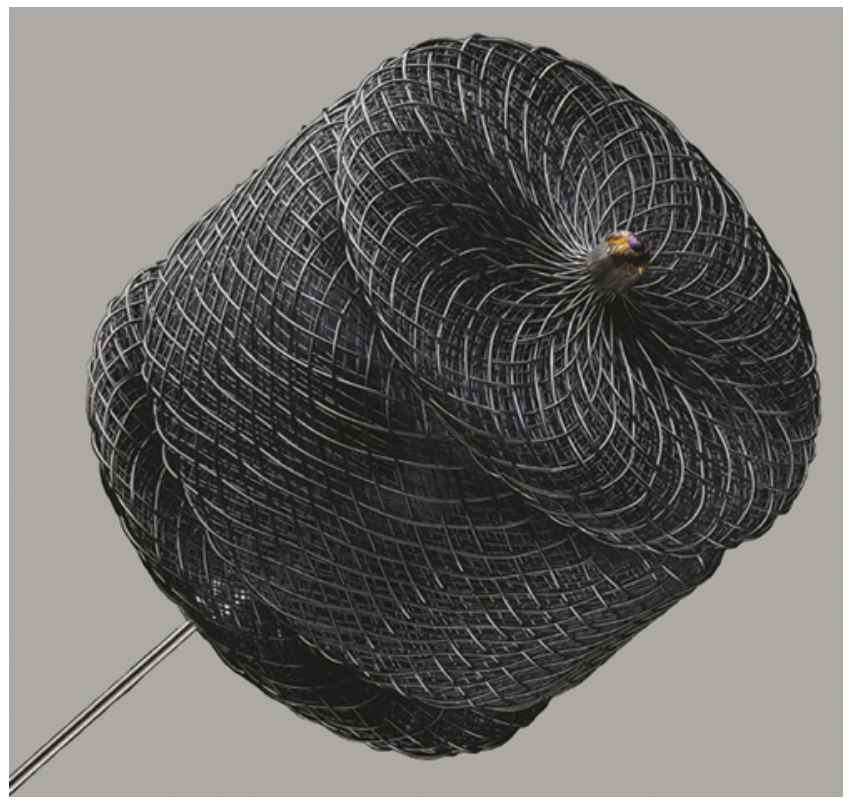

FIG. 5. Endovascular plug used for carotid artery sacrifice. Figure is available in color online only. in rapid vascular occlusion is desirable. In swine models, complete carotid artery occlusion was seen in less than 1 minute after plug deployment.$^{30}$ In humans, the device has been shown to be effective in treating carotid-cavernous fistulas ${ }^{31}$ as well as carotid blowout in patients with head and neck cancer. 28,39

Intracranial pyogenic infections are also known to contribute to the formation of pseudoaneurysms. The ICA lesion in our patient appeared to arise from a direct carotid artery injury rather than the infective process. The intracranial infection in our case was a result of a Potts's puffy tumor, which is typically defined as subperiosteal abscess of the frontal bone that appears as localized swelling of the overlying region of the forehead associated with frontal sinusitis. ${ }^{4,24}$ This infective process results from purulent sinusitis and presents with forehead swelling, with or without systemic symptoms, which may be mistaken for an infected sebaceous cyst or a simple scalp abscess. Typical systemic symptoms include headache, fever, nasal drainage, and frontal sinus tenderness. ${ }^{4}$ Simple scalp drainage can result in recurrent collection or complications from spreading infection. Life-threatening complications from frontal sinusitis include intracranial infection with epidural abscess, subdural empyema, brain abscess, and venous thrombophlebitis. ${ }^{4}$ Subdural empyema and epidural abscess usually require open drainage, with adequate soft-tissue and bony debridement. The use of an endovascular plug obviated the need for antiplatelet agents, which in turn would have led to increased bleeding during craniotomy.

\section{Conclusions}

The endovascular plug is a useful adjunct for emergent large vessel sacrifice, obviating the need for numerous coils and antiplatelet therapy. This technique is particularly useful in the setting of acute pediatric neurosurgical emergencies requiring a concurrent craniotomy and drainage of pus or hematoma. We have shown the safety and feasibility of an endovascular plug in achieving cerebrovascular occlusion.

\section{References}

1. Abruzzo T, Joseph GJ, Owens DS, Dawson RC III, Reid J, Barrow DL: Prevention of complications resulting from endovascular carotid sacrifice: a retrospective assessment. Neurosurgery 46:910-917, 2000

2. Ahuja A, Guterman LR, Hopkins LN: Carotid cavernous fistula and false aneurysm of the cavernous carotid artery: complications of transsphenoidal surgery. Neurosurgery 31:774-779, 1992

3. Auyeung KM, Lui WM, Chow LC, Chan FL: Massive epistaxis related to petrous carotid artery pseudoaneurysm after radiation therapy: emergency treatment with covered stent in two cases. AJNR Am J Neuroradiol 24:1449-1452, 2003

4. Bambakidis NC, Cohen AR: Intracranial complications of frontal sinusitis in children: Pott's puffy tumor revisited. Pediatr Neurosurg 35:82-89, 2001

5. Banfield JC, Shankar JJ: Amplatzer vascular plug for rapid vessel occlusion in interventional neuroradiology. Interv Neuroradiol 22:116-121, 2016

6. Briganti F, Cirillo S, Caranci F, Esposito F, Maiuri F: De- 
velopment of "de novo" aneurysms following endovascular procedures. Neuroradiology 44:604-609, 2002

7. Chalouhi N, Starke RM, Tjoumakaris SI, Jabbour PM, Gonzalez LF, Hasan D, et al: Carotid and vertebral artery sacrifice with a combination of Onyx and coils: technical note and case series. Neuroradiology 55:993-998, 2013

8. Charbel FT, Gonzales-Portillo G, Hoffman W, Cochran E: Distal internal carotid artery pseudoaneurysms: technique and pitfalls of surgical management: two technical case reports. Neurosurgery 45:643-649, 1999

9. Cinar C, Bozkaya H, Parildar M, Oran I: Endovascular management of vascular injury during transsphenoidal surgery. Interv Neuroradiol 19:102-109, 2013

10. Dario A, Dorizzi A, Scamoni C, Cerati M, Balcone Grimaldi G: Iatrogenic intracranial aneurysm. Case report and review of the literature. J Neurosurg Sci 41:195-202, 1997

11. Eckard D, Batnitzky S, Siegel EL: Internal carotid artery sacrifice. Compr Ther 20:113-120, 1994

12. Elhammady MS, Wolfe SQ, Farhat H, Ali Aziz-Sultan M, Heros RC: Carotid artery sacrifice for unclippable and uncoilable aneurysms: endovascular occlusion vs common carotid artery ligation. Neurosurgery 67:1431-1437, 2010

13. Eller JL, Hopkins LN: Use of vascular plug devices in the management of neurovascular emergencies. World Neurosurg 83:9-10, 2015

14. Fiorella D, Albuquerque FC, Woo HH, McDougall CG, Rasmussen PA: The role of neuroendovascular therapy for the treatment of brain arteriovenous malformations. Neurosurgery 59:S3-163-S3-177, 2006

15. Frampas E, Desal HA, Lenoir V, Auffray-Calvier E, De Kersaint-Gilly A: [Endovascular carotid occlusion: a retrospective study of complications in 33 cases.] $\mathbf{J}$ Neuroradiol 27:238-246, 2000 (Fr)

16. Geyik S, Cil BE, Yavuz K, Peynircioglu B, Saatci I, Cekirge S: Neuroapplication of Amplatzer vascular plug: a novel device for parent artery occlusion. Neuroradiology 50:179_ 183,2008

17. Ghatge SB, Modi DB: Treatment of ruptured ICA during transsphenoidal surgery. Two different endovascular strategies in two cases. Interv Neuroradiol 16:31-37, 2010

18. Gralla J, Schroth G, Kickuth R, El-Koussy M, Do DD, Brekenfeld $\mathrm{C}$ : Closing the gap between coil and balloon in the neurointerventional armamentarium? Initial clinical experience with a nitinol vascular occlusion plug. Neuroradiology 50:709-714, 2008

19. Griauzde J, Gemmete JJ, Pandey AS, McKean EL, Sullivan SE, Chaudhary N: Emergency reconstructive endovascular management of intraoperative complications involving the internal carotid artery from trans-sphenoidal surgery. J Neurointerv Surg 7:67-71, 2015

20. Hacein-Bey L, Connolly ES Jr, Duong H, Vang MC, Lazar RM, Marshall RS, et al: Treatment of inoperable carotid aneurysms with endovascular carotid occlusion after extracranial-intracranial bypass surgery. Neurosurgery 41:1225-1234, 1997

21. Hoit DA, Schirmer CM, Malek AM: Use of the Amplatzer vascular plug as an anchoring scaffold for coil-mediated parent vessel occlusion: technical case report. Neurosurgery 59 (1 Suppl 1):ONSE171-ONSE172, 2006

22. Kadyrov NA, Friedman JA, Nichols DA, Cohen-Gadol AA, Link MJ, Piepgras DG: Endovascular treatment of an internal carotid artery pseudoaneurysm following transsphenoidal surgery. Case report. J Neurosurg 96:624-627, 2002

23. Kim BM, Jeon P, Kim DJ, Kim DI, Suh SH, Park KY: Jostent covered stent placement for emergency reconstruction of a ruptured internal carotid artery during or after transsphenoidal surgery. J Neurosurg 122:1223-1228, 2015

24. Kombogiorgas D, Solanki GA: The Pott puffy tumor revisited: neurosurgical implications of this unforgotten entity.
Case report and review of the literature. J Neurosurg 105 (2 Suppl):143-149, 2006

25. Larson PS, Reisner A, Morassutti DJ, Abdulhadi B, Harpring JE: Traumatic intracranial aneurysms. Neurosurg Focus 8(1):e4, 2000

26. Lee W, Shin YS, Kim KH, Kim YB, Hong CK, Chung J: Preliminary experience with vascular plugs for parent artery occlusion of the carotid or vertebral arteries. J Cerebrovasc Endovasc Neurosurg 18:208-214, 2016

27. Lempert TE, Halbach VV, Higashida RT, Dowd CF, Urwin RW, Balousek PA, et al: Endovascular treatment of pseudoaneurysms with electrolytically detachable coils. AJNR Am J Neuroradiol 19:907-911, 1998

28. Macht S, Mathys C, Schipper J, Turowski B: Initial experiences with the Amplatzer Vascular Plug 4 for permanent occlusion of the internal carotid artery in the skull base in patients with head and neck tumors. Neuroradiology 54:61-64, 2012

29. Medel R, Crowley RW, Hamilton DK, Dumont AS: Endovascular obliteration of an intracranial pseudoaneurysm: the utility of Onyx. J Neurosurg Pediatr 4:445-448, 2009

30. Mordasini P, Gralla J, Brekenfeld C, Schroth G, Hoppe H: Preliminary experimental evaluation of the immediate angiographic occlusion time with use of the AMPLATZER Vascular Plug II for carotid artery occlusion. J Vasc Interv Radiol 21:1873-1877, 2010

31. Mordasini P, Schroth G, Brekenfeld C, Fung C, Hoppe H, Gralla J: Endovascular treatment of a traumatic direct carotid-cavernous fistula using the Amplatzer Vascular Plug II. J Endovasc Ther 17:564-568, 2010

32. Osanai T, Bain MD, Toth G, Hussain MS, Hui FK: Balloonaugmented Onyx endovascular ligation: initial human experience and comparison with coil ligation. J Neurointerv Surg 7:608-613, 2015

33. Patel AS, Horton TG, Kalapos P, Cockroft KM: Onyx-HD 500 embolization of a traumatic internal carotid artery pseudoaneurysm after transsphenoidal surgery. J Neuroimaging 25:656-659, 2015

34. Pozzati E, Giuliani G, Poppi M, Faenza A: Blunt traumatic carotid dissection with delayed symptoms. Stroke 20:412416, 1989

35. Prêtre R, Kürsteiner K, Reverdin A, Faidutti B: Blunt carotid artery injury: devastating consequences of undetected pseudoaneurysm. J Trauma 39:1012-1014, 1995

36. Quintana F, Diez C, Gutierrez A, Diez ML, Austin O, Vazquez A: Traumatic aneurysm of the basilar artery. AJNR Am J Neuroradiol 17:283-285, 1996

37. Renn WH, Rhoton AL Jr: Microsurgical anatomy of the sellar region. J Neurosurg 43:288-298, 1975

38. Shakir HJ, Garson AD, Sorkin GC, Mokin M, Eller JL, Dumont TM, et al: Combined use of covered stent and flow diversion to seal iatrogenic carotid injury with vessel preservation during transsphenoidal endoscopic resection of clival tumor. Surg Neurol Int 5:81, 2014

39. Shankar JJ, Maloney WJ, Vandorpe R: Amplatzer vascular plug for occlusion of parent artery in carotid blowout with active extravasation. Interv Neuroradiol 17:224-227, 2011

40. Sim SY, Shin YS, Yoon SH: Endovascular internal trapping of traumatic pericallosal pseudoaneurysm with hydrogelcoated self-expandable coil in a child: a case report. Surg Neurol 69:418-422, 2008

41. Spetzler RF, Carter LP: Revascularization and aneurysm surgery: current status. Neurosurgery 16:111-116, 1985

42. Spetzler RF, Selman W, Carter LP: Elective EC-IC bypass for unclippable intracranial aneurysms. Neurol Res 6:64-68, 1984

43. Sylvester PT, Moran CJ, Derdeyn CP, Cross DT, Dacey RG, Zipfel GJ, et al: Endovascular management of internal carotid artery injuries secondary to endonasal surgery: case series 
and review of the literature. J Neurosurg 125:1256-1276, 2016

44. Tokunaga K, Kusaka N, Nakashima H, Date I, Ohmoto T: Coil embolization of intradural pseudoaneurysms caused by arterial injury during surgery: report of two cases. AJNR Am J Neuroradiol 22:35-39, 2001

45. Tsang ACO: Internal carotid artery injuries secondary to endonasal surgery. J Neurosurg 125:1315-1317, 2016 (Letter)

46. Tseng YY, Yang ST, Yeh YS, Yang TC, Wong HF: Traumatic internal carotid artery pseudoaneurysm mimicking sphenoid sinus tumor. Rhinology 45:332-334, 2007

47. Uzan M, Cantasdemir M, Seckin MS, Hanci M, Kocer N, Sarioglu AC, et al: Traumatic intracranial carotid tree aneurysms. Neurosurgery 43:1314-1322, 1998

48. Vazquez Añon V, Aymard A, Gobin YP, Casasco A, Rüffenacht D, Khayata $\mathrm{MH}$, et al: Balloon occlusion of the internal carotid artery in 40 cases of giant intracavernous aneurysm: technical aspects, cerebral monitoring, and results. Neuroradiology 34:245-251, 1992

49. Wakai S, Yoshimasu N, Eguchi T, Ashikawa R: Traumatic intracavernous aneurysm of the internal carotid artery following surgery for chronic sinusitis. Surg Neurol 13:391-394, 1980

50. Weidenbecher M, Huk WJ, Iro H: Internal carotid artery injury during functional endoscopic sinus surgery and its management. Eur Arch Otorhinolaryngol 262:640-645, 2005
51. Zhang CW, Xie XD, You C, Mao BY, Wang CH, He M, et al: Endovascular treatment of traumatic pseudoaneurysm presenting as intractable epistaxis. Korean J Radiol 11:603611,2010

\section{Disclosures}

The authors report no conflict of interest concerning the materials or methods used in this study or the findings specified in this paper.

\section{Author Contributions}

Conception and design: all authors. Acquisition of data: all authors. Analysis and interpretation of data: Cohen, Manjila, Singh, Ndubuizu, Hsu. Drafting the article: all authors. Critically revising the article: Cohen, Manjila. Reviewed submitted version of manuscript: Cohen, Manjila, Singh. Approved the final version of the manuscript on behalf of all authors: Cohen. Study supervision: Cohen, Manjila.

\section{Correspondence}

Alan R. Cohen, Division of Pediatric Neurosurgery, Department of Neurosurgery, The Johns Hopkins Hospital, 600 North Wolfe St., Phipps 556, Baltimore, MD 21287. email: alan.cohen@ jhmi.edu. 